кандидат экономических наук, доцент, доцент кафедры гуманитарных и социально-экономических дисциплин Великолукской государственной академии физической культуры и спорта

\section{ПУТИ ПОВЫШЕНИЯ КАЧЕСТВА ПРЕДОСТАВЛЕНИЯ МЕДИЦИНСКИХ УСЛУГ НАСЕЛЕНИЮ В РОССИИ}

\begin{abstract}
Аннотация:
Качество медицинских услуг напрямую влияет на уровень и продолжительность жизни населения, биологическую безопасность государства, поэтому важно уделять особое внимание путям повышения качества предоставления медицинских услуг в России. В статье предложены конкретные рекомендации медицинским организациям, позволяющие повысить безопасность и доступность получения медицинских услуг населением страны.
\end{abstract}

Ключевые слова:

медицинская услуга, доступность, безопасность, качество, пациент, медицинская организация, медицинская помощь, Россия.
$\mathrm{PhD}$ in Economics Assistant Professor, Humanitarian, Social and Economic Sciences Department, Velikiye Luki State Academy of Physical Training and Sports

\section{WAYS TO IMPROVE THE QUALITY OF MEDICAL SERVICES TO THE POPULATION IN RUSSIA}

Summary:

The quality of medical services has a direct impact on level and duration of the population life, the biological safety of the state, so it is important to pay special attention to ways of improving the quality of medical services in Russia. The paper provides the specific recommendations to medical organizations in order to increase the safety and the accessibility of medical services to the population of the country.

Keywords:

medical service, accessibility, safety, quality, patient medical organization, medical assistance, Russia.

Медицинская услуга представляет собой комплекс мероприятий, направленных на профилактику, диагностику и в случае необходимости лечение заболеваний. Из этого следует, что медицинской услугой являются не только меры медицинского вмешательства в организм пациента, но и мероприятия по реабилитации пациента. Оказание своевременной медицинской помощи пациенту, согласно Закону № 323-Ф3 «Об основах охраны здоровья граждан в Российской Федерации», представляет собой более обширное понятие. Считается, что медицинская помощь включает в себя ряд медицинских услуг.

Говоря о медицинских услугах, подчеркивают их платность, пытаясь тем самым соединить медицинскую услугу с предпринимательской деятельностью [1, с. 78]. На наш взгляд, это не совсем верно, поскольку в соответствии с нормами законодательства пациентам может предоставляться и бесплатная медицинская помощь, т. е. комплекс бесплатных медицинских услуг, качество которых не всегда уступает качеству платных медицинских услуг.

Вместе с тем оказание медицинских услуг имеет свою специфику, поскольку они связаны с жизнью и здоровьем человека, а сама медицина является одной из сложнейших областей человеческой деятельности и объединяет в себе психологические, физиологические, нравственные, социальные и правовые начала [2, с. 163].

Следует отметить необходимость роста доступности медицинских услуг в России. На практике данное направление можно реализовать за счет:

1) широкого внедрения методов маркетингового исследования, например мероприятия «тайный покупатель», суть которого заключается в сборе достоверной информации о предоставлении медицинских услуг конкретной организацией посредством анкетирования. Данный метод позволит своевременно отслеживать все недочеты в работе медицинских организаций и оперативно их устранять;

2) роста эффрективности работы регистратуры медицинской организации, что подразумевает доведение бытового общения администратора до уровня консультативного приема. На практике это может быть реализовано через внедрение специальных мотивационных программ для персонала медицинских организаций;

3) автоматизации процесса управления медицинской организацией посредством внедрения современных кол-центров, помогающих повысить доступность информации о перечне предоставляемых медицинских услуг и тем самым способствующих своевременному оказанию медицинской помощи пациентам. 
Выполнение предложенных рекомендаций позволит повысить качество предоставления медицинских услуг, поскольку обеспечит своевременный прием претензий пациентов и оперативное устранение недостатков в работе медицинской организации.

Практика ввода подобных мероприятий распространена за рубежом. Благодаря покрытию страховыми взносами стоимости медицинских услуг в США все услуги предоставляются медицинскими организациями на платной основе. Япония, занимающая первое место по потреблению медикаментов на душу населения, демонстрирует высокий показатель продолжительности жизни и низкий уровень младенческой смертности [3, p. 108].

Социальная система страхования Дании позволяет добросовестным гражданам, исправно платящим налоги, своевременно получать медицинские услуги на безвозмездной основе. Более широкий спектр медицинских услуг предлагается в Норвегии, где государство оплачивает стоимость не только медицинских услуг, но и лечебных путевок [4, р. 142].

Многие граждане России также предпочитают проходить курс лечения за рубежом. Причинами этого являются:

- неполучение необходимых медицинских услуг в России и/или прохождение безуспешного лечения;

- советы от высококвалифицированного персонала медицинских организаций;

- отсутствие надлежащего ухода за прооперированным пациентом;

- отсутствие в договоре между пациентом и медицинской организацией пункта об ответственности врача;

- неправильно или несвоевременно установленный диагноз;

- непрозрачность работы платных медицинских организаций;

- ненадлежащий врачебный контроль за развитием заболеваний.

Появление данных причин обусловлено главным образом низким уровнем фринансирования медицинских организаций, что не позволяет им закупать дорогостоящее современное медицинское оборудование и проводить глубокую диагностику здоровья пациентов. Отсутствие ответственности врачей можно объяснить несовершенством законодательства деятельности медицинских организаций. Безуспешность лечения является следствием ненадлежащего уровня безопасности лекарств, многие из которых обладают побочными эффектами. Это произошло вследствие:

- оттока за рубеж высококвалифицированных врачей, мотивированных свободой проведения научных исследований, высокой заработной платой и рабочими местами, укомплектованными современным оборудованием;

- отсутствия ясности при расчете срока окупаемости вложений, что не позволяет медицинским организациям привлекать инвестиции в необходимом количестве;

- высокой стоимости производства лекарств и продолжительного срока создания нового лекарственного препарата;

- отсутствия защиты авторских прав и интеллектуальной собственности;

- присутствия дженериков, заранее снижающих рентабельность производства нового лекарственного препарата.

Реализация путей повышения качества предоставления медицинских услуг населению в России требует выполнения ряда условий, среди которых:

- жесткое государственное регулирование деятельности медицинских организаций, включающее совершенствование нормативно-правовой базы в целях ужесточения ответственности медицинских организаций;

- стимулирование научно-практической деятельности медицинских организаций;

- разработка инновационных программ и проектов для медицинских организаций;

- снижение налогового бремени для медицинских организаций и сотрудничающих с ними предприятий;

- оптимальный график работы персонала медицинской организации;

- совершенствование мотивационной политики персонала медицинских организаций.

Для реализации предлагаемых мероприятий на практике необходимы надлежащее финансирование медицинских организаций, своевременное повышение квалификации врачей, совершенствование законодательства в области ответственности медицинских организаций. Все это позволит медицине России стать сильнейшей в мире, какой она была во время СССР.

Медицина в СССР являлась лучшей в мире по ряду причин:

- развитие профрилактического направления широкого профиля заболеваний;

- предоставление услуг высококвалифицированных специалистов на безвозмездной основе;

- контроль за выполнением гигиенических и санитарных норм;

- строительство и реконструкция оздоровительных центров и домов отдыха; 
- систематическое проведение медицинских осмотров населения с целью профилактики заболеваний;

- государственный контроль за деятельностью медицинских организаций с целью контроля здоровья населения.

Развитие данных направлений, нацеленных на совершенствование качества предоставления медицинских услуг населению, актуально и сегодня, на стадии реформирования системы здравоохранения, когда возможно внесение необходимых поправок в нормативно-правовые акты.

Объединяя все вышесказанное, отметим, что основными путями повышения качества предоставления медицинских услуг населению являются своевременное повышение квалификации персонала медицинской организации, применение препаратов с минимальным набором побочных эффектов, обращение особого внимания на реабилитационный период лечения больного, повышение ответственности врачей за счет совершенствования законодательства, использование высокотехнологичного оборудования и методов, подвергнутых тщательному научному исследованию, доказавших свою безопасность. Все это позволит повысить уровень и качество жизни населения, решить ряд важнейших социально-экономических проблем и усилить биологическую безопасность страны.

\section{Ссылки:}

1. Алексина И.С., Афанасьева Е.С. Продвижение медицинских услуг в социально-экономической среде // Известия Международной академии аграрного образования. 2015. № 21. С. 77-80.

2. Булавицкая Е.В. Отдельные критерии качества медицинских услуг как основа добровольного исполнения обязательств по оказанию медицинских услуг // Евразийский юридический журнал. 2016. № 10 (101). С. 162-165.

3. Kalashnikov K.N., Kalachikova O.N. Accessibility and quality of medical service in the context of health care modernization // Economic and Social Changes: Facts, Trends, Forecast. 2014. No. 2 (32). P. 103-112.

4. Chomoncik M. Emergency medical services in the national firefighting and rescue system. Part III // Bezpieczeństwo i Technika Pożarnicza. 2013. Vol. 31, iss. 3. P. 135-144.

\section{References:}

Aleksina, IS \& Afanasyeva, ES 2015, 'Promotion of medical services in the social and economic environment', Izvestiya Mezhdunarodnoy akademii agrarnogo obrazovaniya, no. 21, pp. 77-80, (in Russian).

Bulavitskaya, EV 2016, 'Certain criteria for the quality of medical services as the basis for voluntary fulfillment of obligations for medical services', Yevraziyskiy yuridicheskiy zhurnal, no. 10 (101), pp. 162-165, (in Russian).

Chomoncik, M 2013, 'Emergency medical services in the national firefighting and rescue system. Part III', Bezpieczeństwo $i$ Technika Pożarnicza, vol. 31, iss. 3, pp. 135-144.

Kalashnikov, KN \& Kalachikova, ON 2014, 'Accessibility and quality of medical service in the context of health care modernization', Economic and Social Changes: Facts, Trends, Forecast, no. 2 (32), pp. 103-112, https://doi.org/10.15838/esc/2014.2.32.10. 